\title{
Fire Suppression of Gasoline Pool Fires Using Metal Oxide
}

\section{Rakhi M S}

Assistant Professor, Division of Safety and Fire Engineering, School of Engineering,

Cochin University of Science and Technology, Kerala, India. Email: rakhimonyland@gmail.com

DOI: http://doi.org/10.38177/ajast.2021.5109

Copyright: (02021 Rakhi M S. This is an open access article distributed under the terms of the Creative Commons Attribution License, which permits unrestricted use, distribution, and reproduction in any medium, provided the original author and source are credited.

\section{ABSTRACT}

Fire suppressants have a great role in controlling fire accidents, with the use of proper fire suppressants, the loss can be greatly reduced. Metal oxides can be used as fire suppressants. A new type of dry powders with capsular structure is to be fabricated for fire suppression, in which the content of water approached $60 \%$. The capsules with the size of 3 5 $\mu \mathrm{m}$ consist of liquid core and solid shell, where the core is water droplet and the shell is assembled silicon dioxide particles with surface hydrophobic modification. Two different scaled real fire tests showed that thus-prepared solid powders could extinguish $0.21 \mathrm{MW}$ gasoline pool fire in $2.0 \mathrm{~s}$ with agent mass of $0.055 \mathrm{~kg}$, and $1.0 \mathrm{MW}$ gasoline pool fire in $5.0 \mathrm{~s}$ with agent mass of $0.49 \mathrm{~kg}$. Such fire extinguishing performance greatly outperformed the conventional mono ammonium phosphate (ABC) powders, neat silica powders and water mist, with significantly reduced fire extinguishing time and mass of agent consumed. Mechanism of the core-shell particles in fire suppression was discussed based on established theories and experimental results.

Keywords: Fire suppressants, Hydrophobic modification, Pool fire, Silica powder, Fire extinguishers.

\section{Introduction}

Highly efficient fire suppressants could fast control the fire and greatly reduce the loss. Since the phase-out of halon, water mist as one of the halon replacer has been paid great attention for its high efficiency and environmental friendliness. As a naturally clean agent, the water mist would not decompose or produce any toxic products when exposed to flame. In comparison to conventional water spray, water mist with much smaller droplet size (with 99\% of the volume of droplets with diameters less than 1000 microns) showed much higher efficiency in fire suppression. But water mist is not so efficient in extinguishing small liquid fuel fires in the open space because a small fire may not be able to generate enough heat for the transformation of water droplets into vapor to displace sufficient oxygen. It is noted that even if a liquid fire is extinguished by water mist, re-ignition may occur at any time for the poor covering the effect of water mist from contacting oxygen.

Droplet size greatly affects the fire suppression capability of water mist. It is difficult for water mist with small droplet size and low momentum to penetrate the flame fume to extinguish the fire. While water mist with big droplet size and high momentum would usually spoil out the liquid fuel or raise its level in a container and so result in a larger combustible area. Production of water mist with proper droplet size was crucial for successful fire extinguishment. Conventionally, the production of water mist depends on specific techniques, such as specially designed nozzles and pressure. This makes the practical application of the water mist conditional. In comparison to water mist, dry powders as fire suppressants even showed superior fire extinguishing capabilities on a mass basis while consuming minimal space. Furthermore, dry powders consisting of small particles could be easily discharged to the flame zone without any special nozzle.

Considering the shortcomings of conventional methods in producing water mist and the advantages of dry powders, here we try to produce a new type of water@ silica capsular particles as a fire suppressant. The water droplets with 
the size of several microns were capsulated by silicon dioxide nanoparticles to form core-shell structures. Under the protection of an outside hydrophobic solid shell, the particles with a high content of water approaching $60 \%$ behaved like dry powder fire suppressants with good flowability. Details of the preparation, physicochemical properties and fire suppression performance of the suppressants were studied. The mechanism of the particles in fire suppression was discussed based on established fire suppression theories.

\section{Materials and Methods}

\subsection{Preparation of Water@silica core-shell structures}

Water@silica core-shell structure is to be formed for experiments. There are mainly three methods:

- Emulsion Method

- Stirr method

- Sol-gel method

\subsubsection{Emulsion method}

Reagent used in this method are TEOS (Tetraethoxysilane), water, OMC (Octyl Methoxy Cinnamate) and apparatus required are Stirrer(1000rpm), Electronic weighing machine.

\section{Procedure}

Mix 50ml TEOS and $100 \mathrm{ml}$ of water together. Both liquids mixed and a mixture obtained.

Stir mixture at $1000 \mathrm{rpm}$ for 50 seconds using a stirrer. The product will be a white milky suspension.

\subsubsection{Sol-gel Method}

Reagents used are TEOS (Tetraethoxysilane), Water (ph 6.6), Ammonium chloride (NH4OH)(catalyst) and Apparatus used are GSA-0.3 high-pressure reactor.

\section{Procedure}

To carry out the reaction under hydrothermal conditions, the GSA-0.3 high-pressure reactor is used. The reactor is designed for scientific and experimental research and chemical reactions in supercritical conditions of high pressure and temperature.

\subsubsection{Stir Method}

The reagent used silicon dioxide $\left(\mathrm{SiO}_{2}\right)$, water and apparatus used stirrer (13000rpm), Electronic weighing machine.

\section{Procedure}

$100 \mathrm{ml}$ of distilled water was weighed. $25 \mathrm{~g}$ of silicon dioxide was weighed. Water and silicon dioxide mixed together and a thick milky solution was obtained. The solution stirred at a rate $0 \mathrm{f} 13000 \mathrm{rpm}$ for 30 seconds using a magnetic stirrer. White free-flowing dust was obtained as the final product. 


\subsection{Feasibility of methods}

Table 2.1

\begin{tabular}{lll}
\hline Emulsion Method & Stir Method & Sol-Gel Method \\
\hline $\begin{array}{l}\text { Huge machines are not } \\
\text { required }\end{array}$ & Huge machines are not required & $\begin{array}{l}\text { Requires huge and complicated } \\
\text { machines likeGSA-0.3 high pressure } \\
\text { reactor }\end{array}$ \\
$\begin{array}{l}\text { Economically feasible } \\
\text { The final product } \\
\text { obtained is a milky white } \\
\text { solution. Application of } \\
\text { final product to fire is } \\
\text { difficult }\end{array}$ & $\begin{array}{l}\text { The final product obtained is white } \\
\text { apply in fire }\end{array}$ & $\begin{array}{l}\text { Economically not feasible } \\
\text { The final product obtained is a milky } \\
\text { white solution. Application of final }\end{array}$ \\
\hline
\end{tabular}

Among these three methods stir method is the most practical and convenient method. So that method is adapted and sample is prepared.

\section{Results and Discussions}

\subsection{X-ray diffraction studies}

Figure 1 showed a typical XRD pattern of as-prepared "dry water" particles, in which only a broad peak with $2 \theta$ centered at about $25^{\circ}$ was seen. It indicated that the material was amorphous $\mathrm{SiO}_{2}$.

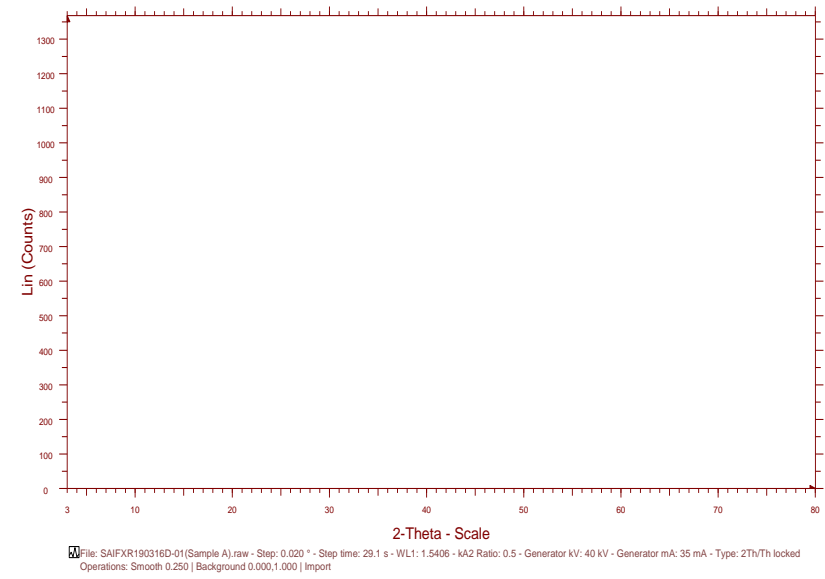

Fig.1.XRD pattern of water@ silica core-shell particles

Presented FTIR spectrum of the sample, where the peaks could be reasonably ascribed to $\mathrm{SiO}_{2}$ and $\mathrm{H}_{2} \mathrm{O}$. The broad band around $3450 \mathrm{~cm}-1$ and the peak at $1640 \mathrm{~cm}-1$ was due to stretching vibration and the bending vibration of 


\section{A DAST}

water molecules adsorbed on the silica surface. The strong band at $1112 \mathrm{~cm}-1$ corresponded to the asymmetric vibration of Si-O-Si. The absorption bands at $800 \mathrm{~cm}-1$ and $485 \mathrm{~cm}-1$ were assigned to the stretching vibration and bending vibration of the Si-O-Si bond, respectively.

\subsection{Scanning Electron Microscopy}

Scanning electron microscopy (SEM) is often used for surface analysis and imaging. From the SEM image (Fig 2), it can be detected the sample consisted of free-flowing powders. Optical microscopy images showed that the particles were spherical and ellipsoidal with the size in the range of $20 \sim 50 \mu \mathrm{m}$. SEM images gave more details of the particles, revealing that the particle shell was made up of loosely arranged small particles.
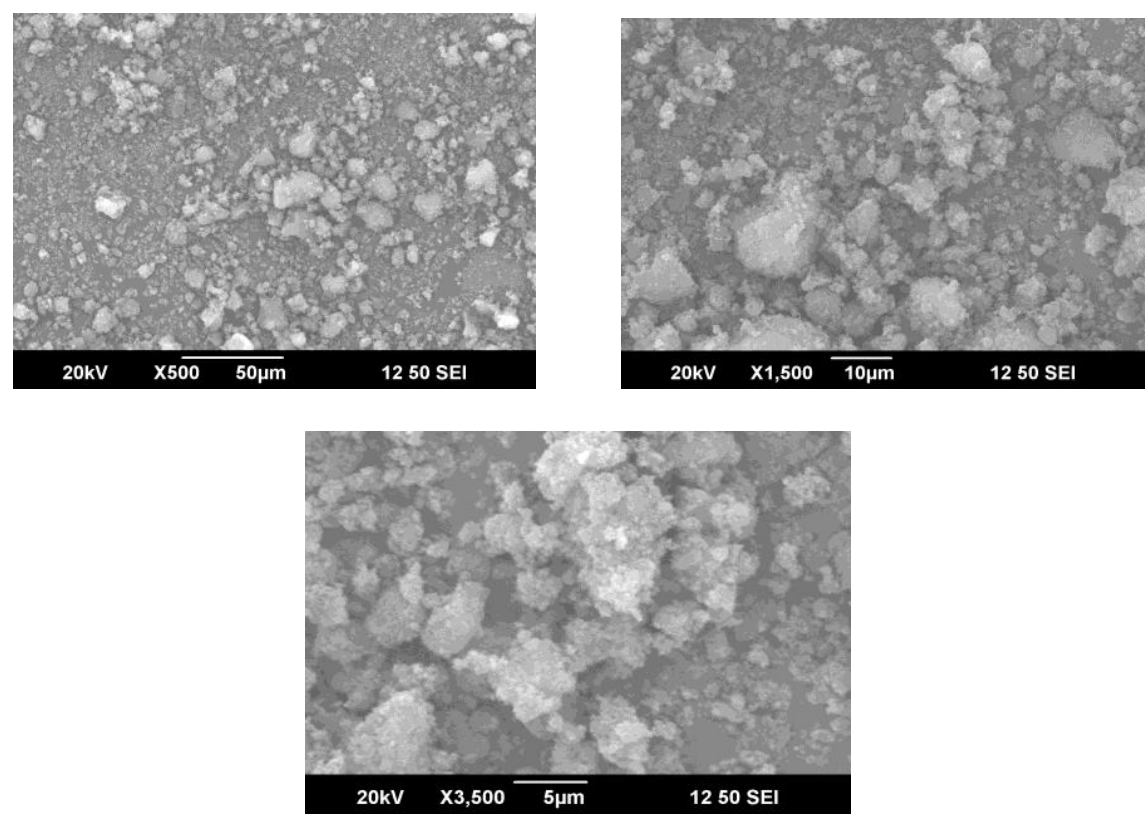

Fig.2. SEM images of water@ silica core-shell particles

\subsection{Practical test to analyse the fire extinguishing properties of the sample}

\subsubsection{Fire test}

Generally, the standard testing procedures for evaluating the fire extinguishing performance of dry powders include ISO 7202-2012, NFPA 17, ANSI/UL 299, and etc. However, in these standards, the experimental setup is quite large which is expensive and time-consuming to build. For the limit of experimental conditions, large fire tests following these standards were difficult to undertake. Two laboratory scaled tests were designed with relatively small fire sources and fewer agents to reduce the cost. But the test methods were basically in conformance with the regulations in international standards.

\subsubsection{Small scale fire test}

The small scale fire tests, were conducted in a $27 \mathrm{~m} 3(3 \mathrm{~m} \times 3 \mathrm{~m} \times 3 \mathrm{~m})$ confined space with natural ventilation. Gasoline was contained in the oil pan with a diameter of $0.50 \mathrm{~m}$. A thermocouple tree, containing six thermocouples with the interval of $0.20 \mathrm{~m}$ and the lowest thermocouple $0.25 \mathrm{~m}$ above the fuel pan, was set up to measure the flame temperatures. In each test, $200.0 \mathrm{~g}$ powders were added into a tank with a volume of $1000 \mathrm{ml}$ and 


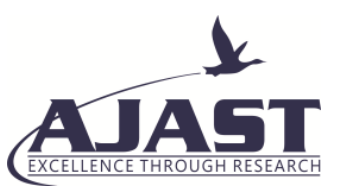

Asian Journal of Applied Science and Technology (AJAST)

Volume 5, Issue 1, Pages 82-87, January-March 2021

pressurized by nitrogen to a pre-assigned value of $0.50 \mathrm{MPa}$. Before powder discharging, $400 \mathrm{ml}$ gasoline was added into the pan, ignited and pre-burned for $30 \mathrm{~s}$. The flame power was estimated as $0.21 \mathrm{MW}$. The distance from the extinguisher nozzle to the pan center was set as $1.0 \mathrm{~m}$. The valve of the powder tank was turned off as soon as the fire was extinguished. The weight of the tank was measured before and after each test to determine the total mass of suppressants consumed for fire extinguishment. Each test was repeated at least three times to get a converged result.

\subsubsection{Open fire test}

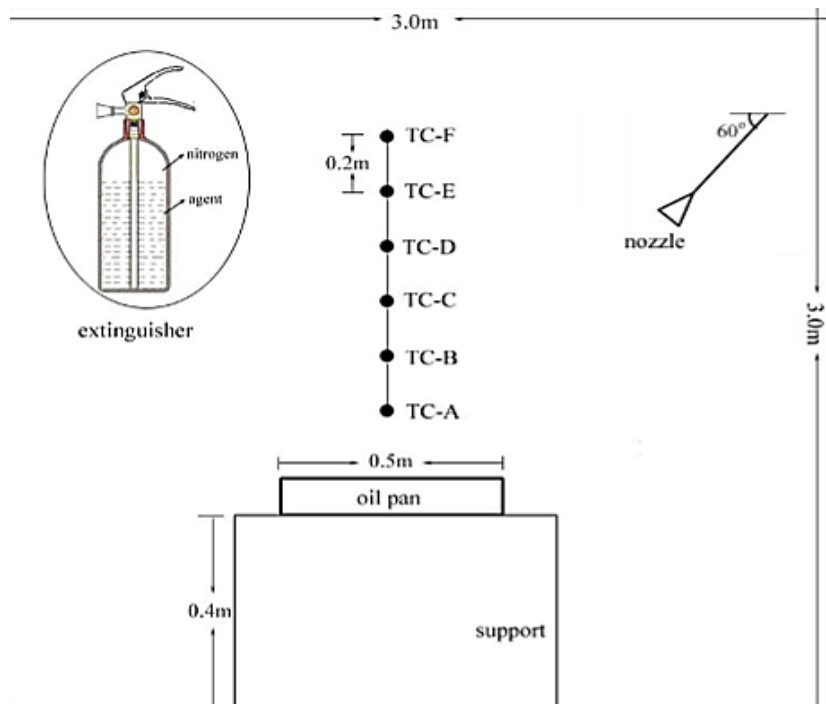

The bigger scale fire tests were conducted in a large space with natural ventilation to further evaluate fire extinguishing performance of as-prepared powders. $200 \mathrm{~g}$ powders were contained in a hanged powder extinguishing equipment and pressurized by nitrogen to $1.0 \mathrm{MPa}$. The circular oil pan contained $150 \mathrm{ml}$ gasoline. The perpendicular distance from the hanged extinguisher nozzle to the fuel surface was $1.5 \mathrm{~m}$. The gasoline was ignited and pre-burned for $30 \mathrm{~s}$ before powder discharging. After the fire was extinguished, the agent mass-consumed was measured and recorded.

\section{Conclusion}

Fire suppressants have a great role in controlling fire accidents, with the use of proper fire suppressants, the loss can be greatly reduced. Metal oxides can be used as fire suppressants. A new type of dry powders with capsular structure is to be fabricated for fire suppression, in which the content of water approached $60 \%$. The capsules with the size of $3 \sim 5 \mu \mathrm{m}$ consist of liquid core and solid shell, where the core is water droplet and the shell is assembled silicon dioxide particles with surface hydrophobic modification. Two different scaled real fire tests showed that thus-prepared solid powders could extinguish $100 \mathrm{ml}$ gasoline pool fire in $2.7 \mathrm{~s}$ with an agent mass of $200 \mathrm{~g}$. Such fire extinguishing performance greatly outperformed the conventional mono ammonium phosphate (ABC) powders, neat silica powders and water mist, with significantly reduced fire extinguishing time and mass of agent consumed. Considering the shortcomings of conventional methods in producing water mist and the advantages of dry powders, here we try to produce a new type of water@ silica capsular particles as fire suppressant. The water droplets with size of several microns were capsulated by silicon dioxide nanoparticles to form core-shell structures. Under the protection of outside hydrophobic solid shell, the particles with a high content of water approaching $60 \%$ 
behaved like dry powder fire suppressants with good flowability. Details of the preparation, physicochemical properties and fire suppression performance of the suppressants were studied. The mechanism of the particles in fire suppression was discussed based on established fire suppression theories.

\section{Declarations}

\section{Source of Funding}

This research did not receive any specific grant from funding agencies in the public, commercial, or not-for-profit sectors.

\section{Competing Interests Statement}

The authors declare no competing financial, professional and personal interests.

\section{Consent for publication}

We declare that we consented for the publication of this research work.

\section{Code availability}

The programming code that we have used for this research is available and authors are willing to share when it is required.

\section{References}

[1] Xiaomin Ni, Shaogang Zhang, Zhong Zheng, Xishi Wang, “Application of Water@ Silica Core-Shell Particles for Suppressing Gasoline Pool Fires”.

[2] Jenny Alongi, Jennifer Tata, Federico Carosio, Giuseppe Rosace, Alberto Frache and Giovanni Camino, "A Comparative Analysis of Nanoparticle Adsorption as Fire-Protection Approach for Fabrics".

[3] Mahr T., Hubert, B. Schartel, H. Bahr, M. Sabel, H. Militz, "Fire retardancy effects in single and double layered sol-gel derived $\mathrm{TiO} 2$ and $\mathrm{SiO} 2-$ wood composites".

[4] http://www.columbusfire.net/fire/gasoline.asp

[5] Matheson Gas. Lower and Upper Explosive Limits for Flammable Gases and Vapors (LEL/UEL). Available at: http://www.mathesongas.com/pdfs/products/Lower-(LEL)-\&-Upper-(UEL)-Explosive-Limits-.pdf. Accessed November $10^{\text {th }}, 2013$.

[6] B. Evarts, Fires at U.S. Service Stations, NFPA reports, 2011.

[7] A. K. Kim, Advances in Fire suppression systems, National Research Council Canada NRCC-52712, 2009.

[8] W. K. Chow, Y. Gao, H. Dong, G. Zou, L. Meng, (SNWMFS1) Will water mist extinguish a liquid fire rapidly? Archit. Sci. Rev. 46 (2003) 139-144.

[9] A. K. Kim, Improvement of water mist performance with foam additives, in: Fire Suppression and Detection Research Application Symposium, Orlando, FL., Feb. 7-9, 2001.

[10].J. R. Mawhinney, B. Z. Dlugogorski, A. K. Kim, A closer look at the fire extinguishing properties of water mist, in: Proceedings of the Fourth International Symposium on Fire Safety Science, 1997, p. 47-60. 